\title{
Identification of Cobalamin Binding Protein Synthesized de novo by Gastric Cancer Cells
}

\author{
Yoshio WaKatsuki,,${ }^{1, *}$ Masami InAda, ${ }^{1}$ Hiroyuki Kudo, ${ }^{1}$ Gakuji Oshio, ${ }^{2}$ \\ Toru MASUDA, ${ }^{3}$ and Toru KITA ${ }^{1}$
}

Departments of Geriatric Medicine, ${ }^{1}$ Pathology, ${ }^{2}$ and Institute of Immunology, ${ }^{3}$ Faculty of Medicine, Kyoto University, Kyoto 606, Japan

(Received March 6, 1989)

\begin{abstract}
Summary The content of cobalamin-binding protein (Cb1BP) was measured in stomach extracts and various cell lines. CblBP was increased in the cancer extract compared with non-cancerous control. The level of CblBP was also increased in serum-free culture medium of a gastric cancer cell line, but was almost undetectable in media of control cell lines. This output of Cb1BP in medium was suppressed by cycloheximide. These Cb1BPs were immunologically cross-reactive with anti saliva $\mathrm{R}$ binder antibody. The $M_{\mathrm{r}}$, determined by immunoprecipitation, was 70 $\mathrm{kDa}$ and the $\mathrm{pI}, 2.8-3.2$. From these properties, this Cb1BP in cancer cells was considered to be an isoprotein of the cobalamin $\mathrm{R}$ binder. Histochemical studies showed that immunoreactive Cb1BP was confined to cytosol of cancer cells and cells in metaplasia. The present results suggest that $\mathrm{Cb} 1 \mathrm{BP}$ of the $\mathrm{R}$ binder type is synthesized de novo in some type of gastric cancer cells and in metaplastic cells.
\end{abstract}

Key Words: cobalamin binding protein, serum-free culture, immunoprecipitation, immunohistochemistry, $\mathrm{R}$ binder

Human cobalamin $\left(\mathrm{B}_{12}\right)$-binding protein can be divided into three classes [1]: (1) gastric intrinsic factor, which facilitates $B_{12}$ absorption from the small intestine; (2) plasma transcobalamin II, which facilitates cellular uptake of $B_{12}$ by tissue; and (3) $\mathrm{R}$ binders, which are found in several body fluids and tissues but whose role in cellular metabolism of cobalamin remains largely a matter of conjecture. Plasma transcobalamin I and -III are considered immunologically equivalent to $\mathrm{R}$ binder. The term "R protein" was first used by Graesbeck et al. [2] to identify in human

*To whom correspondence should be addressed. 
gastric juice a $\mathrm{B}_{12}$-binding protein without intrinsic factor (IF) activity. A recent report has indicated the absence of $\mathrm{R}$ binder in the gastric juice obtained with gastrostomy tubes from patients with complete obstructin to swallowing [3]. Our preliminary studies showed, however, the presence of non-IF-binding protein in the gastric juice and stomach extract obtained from cancer patients $[4,5]$. In these regards, a study was undertaken to elucidate derivation and physicochemical characters of Cb1BP in the stomach of cancer patients.

\section{MATERIALS AND METHODS}

Extraction of binding protein. Stomach tissues were obtained from a 56year-old female with gastric cancer and from a 22-year-old male with a perforated duodenal ulcer. In the former, separate homogenates were prepared from the carcinoma itself and the scrape of mucosa adjacent to the tumor that was not histologically involved in the cancer, though it contained a small metaplastic area. Each specimen was minced by Biomixer (Nissei, Tokyo) for $5 \mathrm{~s}$ and homogenized in extraction buffer $(6 \mathrm{ml} / \mathrm{g}$ specimen) with a Teflon pestle for $15 \mathrm{~s}$ at $1,500 \mathrm{rpm}$ on the ice. Extraction buffer consisted of $50 \mathrm{~mm}$ Tris- $\mathrm{HCl}(\mathrm{pH} 7.5)$ with $0.25 \mathrm{~mm}$ sucrose, $5 \mathrm{~mm}$ EDTA, $5 \mathrm{~mm}$ EGTA, $2 \mathrm{~mm}$ phenylmethylsulphonyl fluoride, $2 \mathrm{~mm}$ pepstatin, and $0.5 \%$ Triton X-100. Homogenates were gently stirred for $6 \mathrm{~h}$ at $4^{\circ} \mathrm{C}$ and centrifuged at $20,000 \times g$ for $1 \mathrm{~h}$. Supernatants were stored at $-80^{\circ} \mathrm{C}$. All specimens used were obtained with the patient's prior consent.

Serum-deprived culture. We used gastric cancer cell line KATOH-III, which was generously provided by Dr. M. Sekiguchi, Institute of Medical Science, the University of Tokyo [6], HeLa cells (CCL-2; ATCC), and Intestine 407 (CCL-6) as controls. The cells were maintained in suspension in medium consisting of 45\% DMEM, 45\% RPMI-1640, 10\% heat-inactivated FCS, $200 \mathrm{~mm} /$ liter glutamine, streptomycin $(100 \mu \mathrm{g} / \mathrm{ml})$ and penicillin $\mathrm{G}$ (100 units $/ \mathrm{ml})$, and were split at a $1: 10$ ratio at weekly intervals. After subconfluent growth, cells were harvested, washed three times in Hanks' balanced salt solution, then cultured again at a density of $1 \times 10^{5} / \mathrm{ml}$ in supplemented serum-free medium (SSFM) consisting of DMEM containing $5 \mu \mathrm{g} / \mathrm{ml}$ insulin (Sigma, MO), $5 \mu \mathrm{g} / \mathrm{ml}$ transferin (Sigma), $1 \%$ non-essential amino acids (Flow Laboratory, VA), and antibiotics [7, 8]. Spent medium was taken after 1 week, and concentrated about a hundred fold using an Amicon membrane (YM-10). There were no striking changes in cell viability after 1 week in SSFM.

Assay of vitamin $\mathrm{B}_{12^{-}}$and cobalamin binding capacity. Unsaturated $\mathrm{B}_{12^{-}}$ binding capacity (UBBC) was measured by a modified albumin-coated charcoal method [9]. Saturated binding capacity was calculated from endogenous Cbl determined by radioassay (Immophase, Corning, MA). The results of both assays were expressed as concentration of binder-equivalent cobalamin $(\mathrm{pg} / \mathrm{ml})$. In some experiment, we carried out the UBBC assay at various pH's in PBS, and measured endogenous $\mathrm{Cbl}$ in peak column-fraction of cancer extract before and after 
adsorption of TC-II onto Silica Quso [10], thereby this cobalamin binding protein was discriminated from TC-II.

Gel filtration and purification of Cb1BP. One milliliter of samples $(2.0 \mathrm{mg}$ protein $/ \mathrm{ml})$ was incubated with $20 \mu \mathrm{l}$ of $\left[{ }^{57} \mathrm{Co}\right]$ cyanocobalamin $(210.0 \mu \mathrm{Ci} / \mu \mathrm{g}$, $36.2 \mathrm{pmol} / \mathrm{ml}$, Amersham, UK) for $30 \mathrm{~min}$ at room temperature, applied to a Sephadex G-200 (SG-200) column, and eluted as described elsewhere [9, 11]. Immunological crossreactivity was examined by the same column chromatography; radiolabeled materials mentioned above were incubated again with appropriate amount of antisera for $30 \mathrm{~min}$ at room temperature before application to the column, thus antigen-antibody reaction was detected by a shift of the appropriate binder peak toward the void fraction [9]. For purification of binding protein, Cbl-Sepharose affinity chromatography was carried out according to the method described by Allen and Majerus [12].

Isoelectric focusing. Radioactive peaks, except free cobalamin, in SG-200 gel filtration were analyzed by polyacrylamide rod gel electrophoresis with a $\mathrm{pH}$ gradient of 2.5-5.0, which was made by using Pharmalyte (Pharmacia, Uppsala) [13]. After optimal focusing was obtained, the gel was sectioned into 5-mm slices and assayed for radioactive $\mathrm{B}_{12}$. The $\mathrm{pH}$ gradient across each gel was determined by elution of each slice with distilled water $(1 \mathrm{ml})$ for $24 \mathrm{~h}$ and direct measurement of the $\mathrm{pH}$ value of the eluants.

Preparation of antibodies. Anti-intrinsic factor antibody was prepared from serum of a patient with pernicious anemia. Rabbit anti-R antibody (RAR) was raised against affinity-purified saliva $\mathrm{R}$ binder. Antisera were fractionated by anion-exchange chromatography (Whatman; DE32).

Immunoprecipitation. Saliva and plasma were obtained from healthy volunteers. Saliva, conditioned SSFM of KATOH-III (K-SSFM), gastric cancer extract, and extracts of non-cancerous mucosa both with and without metaplasia were radioiodinated by the lactoperoxidase method [14]. Radio-labeled materials were then immunoprecipitated with RAR and Protein A Sepharose overnight at $4{ }^{\circ} \mathrm{C}$ according to a previously described procedure [15]. Final precipitates were analyzed by SDS-PAGE and autoradiography.

Immunostaining. Sections of formalin-fixed and paraffin-mounted cancer tissue, normal stomach tissue, and KATOH-III smears were stained by the indirect peroxidase technique. Deparaffinized sections and cell smears were treated with $0.3 \%$ hydrogen peroxide in absolute methanol for $20 \mathrm{~min}$ for blocking of endogenous peroxidase activity. After blocking the non-specific binding of immunoglobulin by incubation in $10 \%$ normal goat serum for $1 \mathrm{~h}$, we further incubated sections and smears with RAR at a dilution of $1: 500$ overnight at $4^{\circ} \mathrm{C}$, followed by treatment with peroxidase-conjugated goat anti-rabbit IgG antiserum (Cappel, CA) at a dilution of $1: 100$, at room temperature for $30 \mathrm{~min}$. The histochemical determination of peroxidase was carried out according to the modified method of Graham and Karnovski [16]. 


\section{RESULTS}

\section{Gel filtration}

In either cancer or control extracts, UBBC was less than $10 \%$ of the total binding capacity. A large peak with estimated molecular weight of $120 \mathrm{kDa}$ was observed in both cancer extract and K-SSFM (Fig. 1A and C). In the control extract, binders caused a broad-based peak at $80-90 \mathrm{kDa}$ with a small shoulder at $120 \mathrm{kDa}$ (Fig. 1B). Free Cbl was eluted at the end of the column run. In condi-

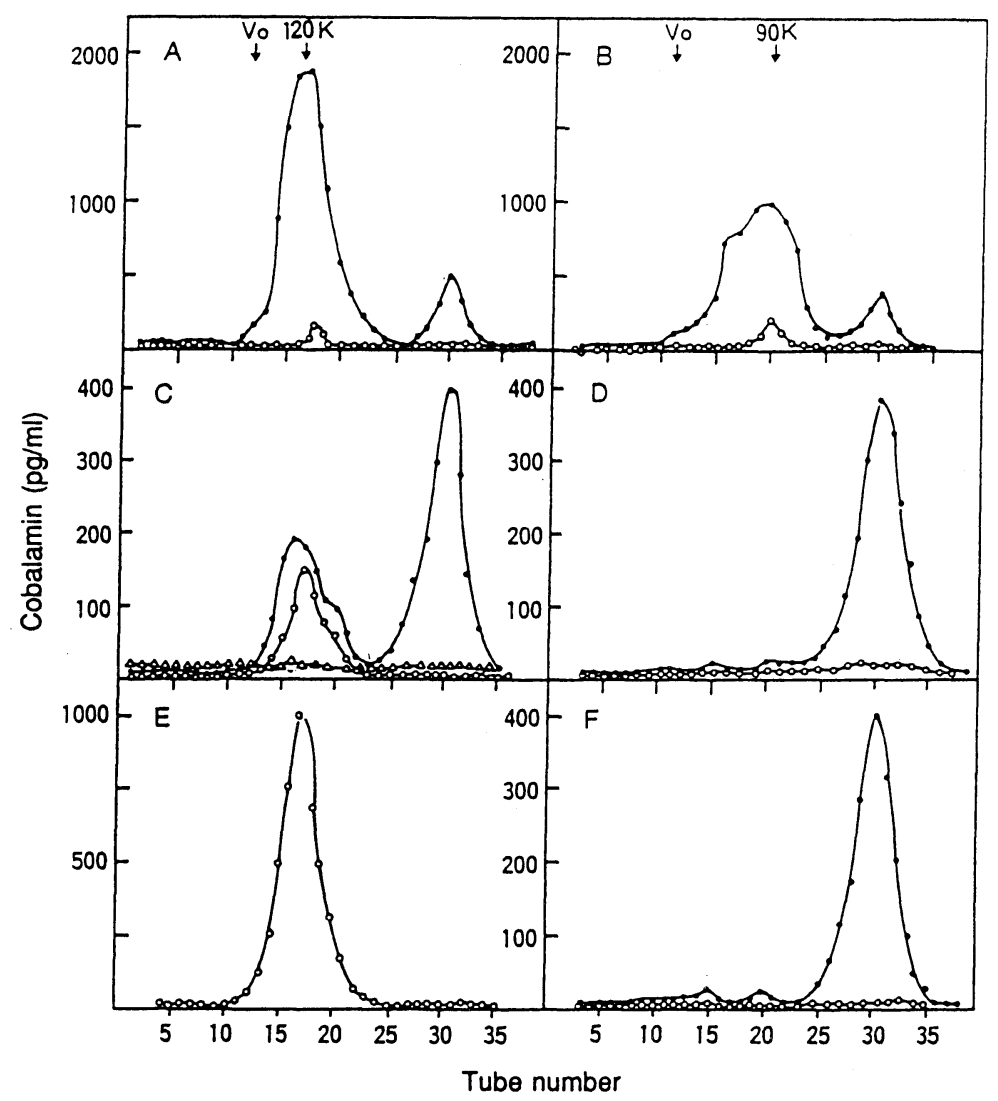

Fig. 1. Elution profiles of $\left[{ }^{57} \mathrm{Co}\right] \mathrm{B}_{12}$-labeled samples. Labeled samples of $1 \mathrm{ml}$ were applied to a column $(1.4 \times 28 \mathrm{~cm})$ of Sephadex G-200 equilibrated and eluted with $0.05 \mathrm{M}$ potassium phosphate $(\mathrm{pH} 7.4)$ containing $0.5 \mathrm{M} \mathrm{NaCl}$. Concentration of endogenous cobalamin $(\bullet \bullet)$ and UBBC $(\bigcirc-\circ)$ were determined for each fraction $(2.5$ $\mathrm{ml}$ ); cobalamin due to $\left[{ }^{57} \mathrm{Co}\right] \mathrm{B}_{12}$-labeling was subtracted in endogenous cobalamin assay. A, Cancer extract; B, extract from non-cancerous mucosa adjacent to tumor; C, SSFM of KATOH-III; D, SSFM of Intestine 407; E, saliva; F, SSFM of HeLa cell; in $\mathrm{C}$, cycloheximide was added $(5 \mu \mathrm{g} / \mathrm{ml})(\triangle-\triangle)$; Vo, void volume; Apparent molecular weight was estimated from calibration kit markers. 
tioned SSFM, UBBC was markedly elevated in KATO-III (Fig. 1C), but was at almost background level in the case of Intestine 407 (Fig. 1D) and HeLa cell (Fig. $1 \mathrm{~F})$. Cycloheximide, at a concentration as small as $5 \mu \mathrm{g} / \mathrm{ml}$ in culture medium, suppressed the UBBC in K-SSFM. In the cancer extract and K-SSFM, the main radioactive peak was eluted at the void volume only when samples had been incubated with RAR (Fig. 2A and E). In the control extract, however, the major peak binder reacted with anti-intrinsic factor antibody and the small peak binder (at the shoulder of the main peak) reacted with RAR (Fig. 2C and D). Unsaturated binding capacity in the cancer extract and in K-SSFM were relatively stable in the $\mathrm{pH}$ range of 3.0-11.0; retention of binding capacity was $88 \%$ at $\mathrm{pH} 3.0$ and $85 \%$ at $\mathrm{pH} 11.0$ when $100 \%$ capacity was defined as the level at $\mathrm{pH} 7.4$. The level of endogenous cobalamin in peak fraction of cancer extract before and after silicaadsorption were $1,980 \pm 108.5(\mathrm{pg} / \mathrm{ml})$ and $1,834.7 \pm 125.4(\mathrm{pg} / \mathrm{ml})$, respectively, in quadruplicate assays.

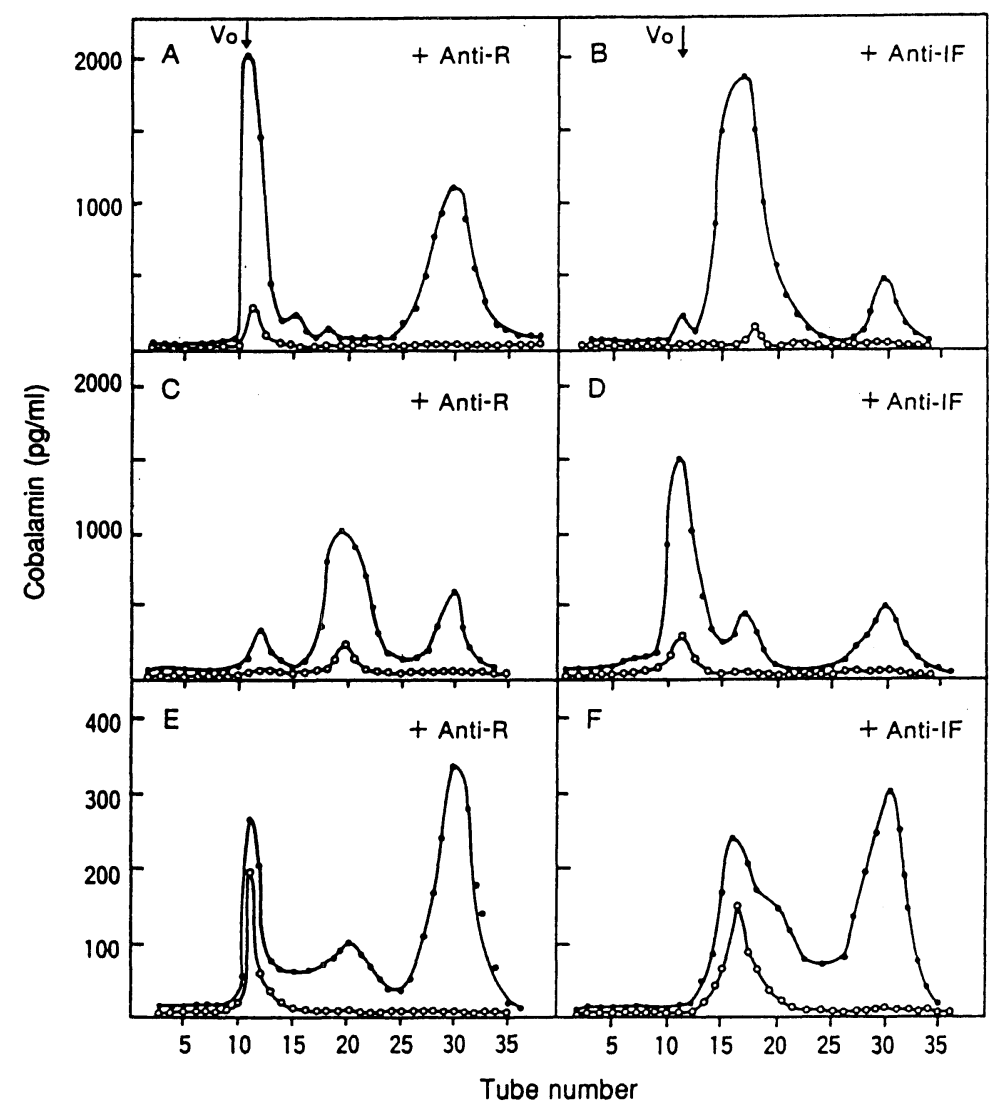

Fig. 2. Elution profiles of radiolabeled and antiserum-incubated samples. $(\bullet \bullet)$, Endogenous cobalamin; $(\bigcirc-\infty)$, UBBC; A and B, Cancer extract; $C$ and D, control extract; E and F, K-SSFM; for experimental details, see "Materials and Methods" section. 


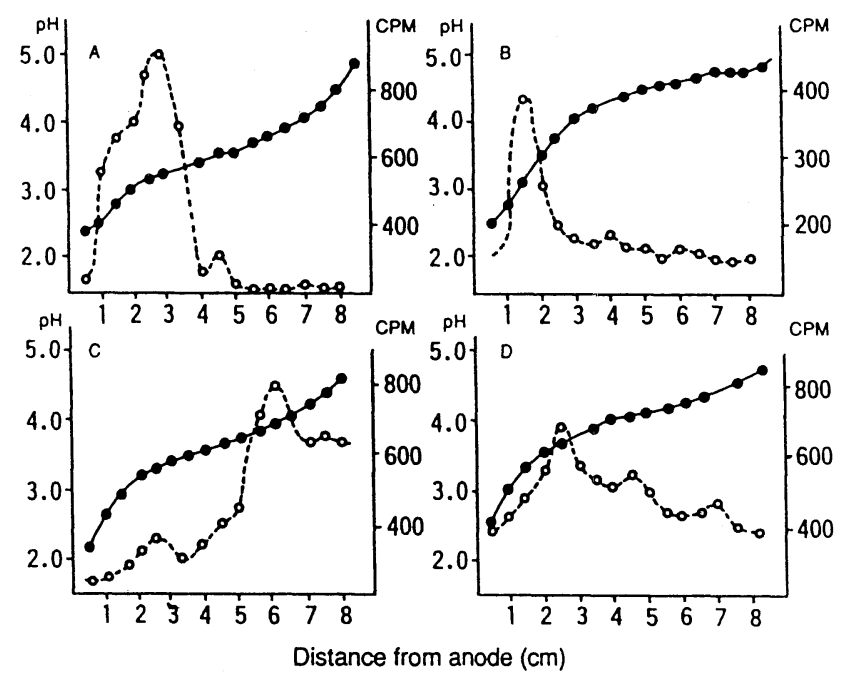

Fig. 3. Isoelectric focusing of SG-200 gel-fractionated samples. Electrophoresis was started with an initial voltage of $200 \mathrm{~V}$ for $1 \mathrm{~h}$ and $300 \mathrm{~V}$ for $5 \mathrm{~h}$ and finally $400 \mathrm{~V}$ for $1 \mathrm{~h}$. A, Cancer extract (fraction no. 16 in SG-200 filtration); B, K-SSFM (no. 16); C, saliva (no. 16); D, control extract (no. 20). ---, pH; -O-, CPM.

\section{Isoelectric focusing}

Isoelectric points $(\mathrm{pI})$ of the binder in the cancer extract were distributed between 2.8 and 3.8. Other pIs determined were as follows: 3.2 in K-SSFM, 3.6 and 5.0 in the control extract (with and without metaplasia, respectively), and 3.8-4.3 in saliva (Fig. 3).

\section{Immunoprecipitation}

RAR immunoprecipitated an essentially identical $70 \mathrm{kDa}$ molecule in all samples studied except in the extract obtained from the young patient with duodenal ulcer (Fig. 4).

\section{Immunostaining}

In stomach tissue, positive staining was confined to the cytosol of cancer cells, and to goblet and columnar epithelial cells in the area showing intestinal metaplasia, but no significant staining was observed in normal stomach mucosa (Fig. 5). In cell smears from KATOH-III, positive staining was also observed in the cytosol.

\section{DISCUSSION}

We observed an increased level of Cb1BP in the gastric cancer extract. Binding capacity of this CblBP was acid resistant and not adsorbed onto Silica Quso, 


\section{$\begin{array}{llllll}1 & 2 & 3 & 4 & 5 & 6\end{array}$}

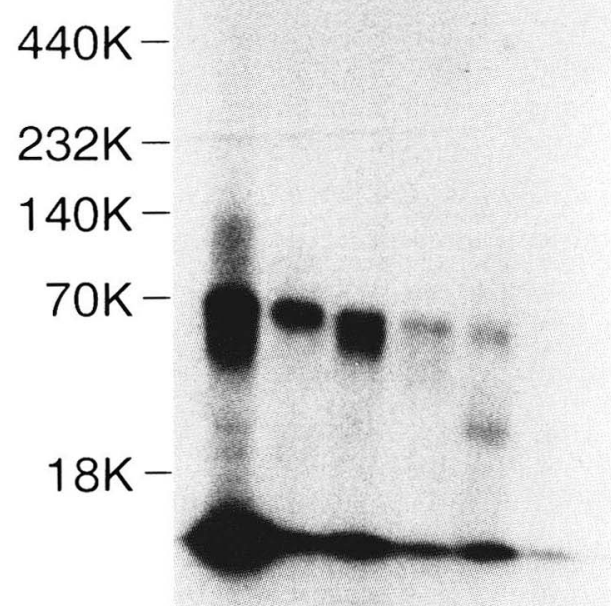

Fig. 4. Immunoprecipitation with anti-R antibody. 1, Saliva; 2, K-SSFM; 3, extract of gastric cancer; 4, extract of control mucosa with intestinal metaplasia; 5, plasma; 6, extract of control mucosa (without metaplasia) from patient with ulcer. Molecular weight values were determined by a calibration kit.

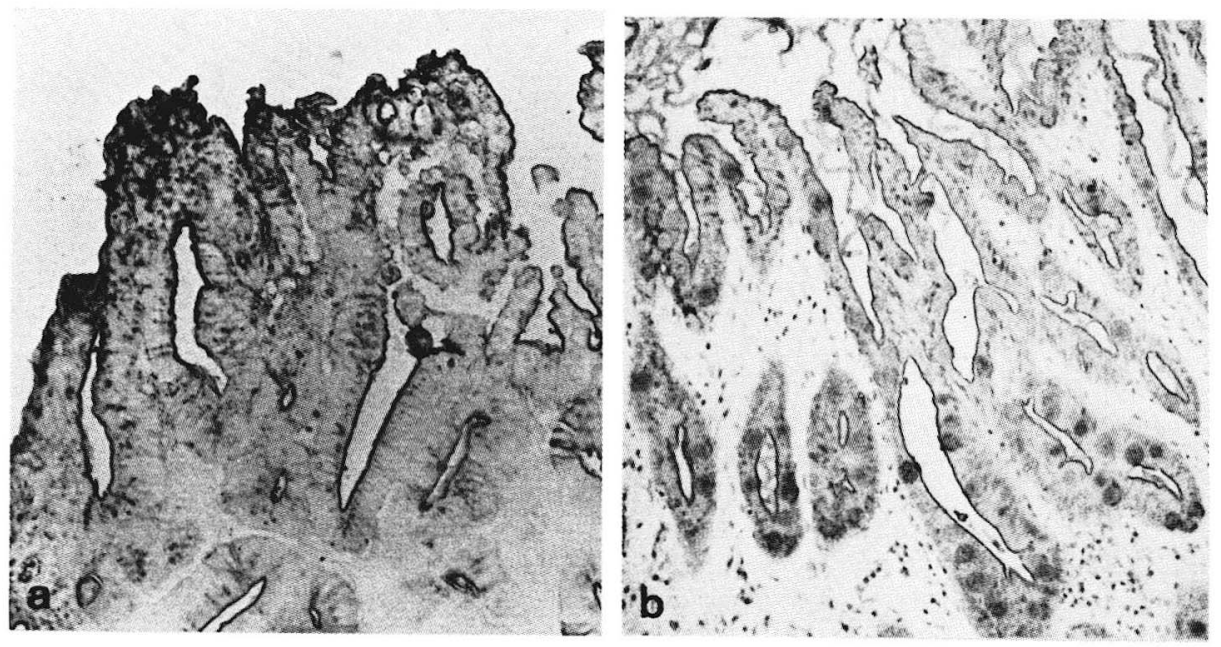

Fig. 5. Immunoperoxidase staining for $\mathrm{R}$ binder in the gastric mucosa. (a) Papillary adenocarcinoma, and (b) intestinal metaplasia. Counterstained with methyl green.

Vol. 7, No. 1, 1989 
which discriminated this Cb1BP from TC-II.

To exclude plasma-derived factors, granulocytes and saliva, we have included studies on cell lines cultured in serum-free medium. An increase in holo- and apo-binding capacities was observed in the medium from a gastric cancer cell line but not in that from controls. These binding capacities became undetectable in the presence of cycloheximide in the culture medium.

Binding capacities in the cancer extract and K-SSFM were acid resistant and not adsorbed to silica, which was discriminative from that of TC-II.

Chromatographic and immunological properties of these $\mathrm{Cb} 1 \mathrm{BP}$ in the cancer extract and K-SSFM were very similar to those of R binder, although the pIs of the former were more acidic than the $\mathrm{pI}$ of saliva $\mathrm{R}$. The $M_{\mathrm{r}}$ determined by immunoprecipitation and SDS-PAGE were the same as that of saliva R.

In histochemical studies, immunoreactive $\mathrm{R}$ binder was detected in the cytosol of cancer cells and in cells showing intestinal metaplasia.

All these lines of evidences suggest that gastric cancer cells de novo synthesize a Cb1BP that has the properties of an isoprotein of $\mathrm{R}$ binder.

In the present study, a $70 \mathrm{kDa}$ Cb1BP was immunoprecipitated in the extracts of carcinoma and mucosa with intestinal metaplasia, but not in the extract of mucosa without intestinal metaplasia. Our recent work demonstrated that immunoreactive $\mathrm{R}$ binder was not detected in normal stomach mucosa but was found in goblet cells of the colon and in surface epithelium of the small intestine [17]. Therefore, this binder-production by gastric mucosa may suggest a common histogenetic background for intestinal metaplasia and some type of gastric cancer [18].

$\mathrm{R}$ binders from various sources are known to have the same protein backbone and microheterogeneous carbohydrate moieties [19, 20], and cancer-associated aberrant glycosylation of glycolipids and glycoproteins have been recently reported $[21,22]$. In these regards, studies are now in progress to elucidate the structural alterations of carbohydrate residues that are probably responsible for the lower pI values of the cancer derived $\mathrm{R}$ binder.

\section{REFERENCES}

1. Jacob, E., Baker, S.J., and Herbert, V. (1980): Vitamin $\mathrm{B}_{12}$-binding proteins. Physiol. Rev., 60, $918-960$.

2. Graesbeck, R., Simon, K., and Sinkkonen, I. (1966): Isolation of intrinsic factor and its probable degradation product, as their vitamin $\mathrm{B}_{12}$ complexes, from human gastric juice. Biochim. Biophys. Acta, 127, 47-58.

3. Herzlich, B., and Herbert, V. (1986): Rapid collection of human intrinsic factor uncontaminated with Cobalophilin (R binder). Am. J. Gastroenterol., 81, 678-680.

4. Wakatsuki, Y., Inada, M., Kudoh, H., Seki, M., and Miyake, T. (1985): Characterization of cobalamin binding protein produced by human gastric cancer cell line. Proc. Jpn. Cancer Assoc., 44, 447 (in Japanese).

5. Inada, M., Miyake, T., Kudo, H., Wakatsuki, Y., Murakami, M., Seki, M., Mizuno, M., Tsukada, H., and Okae, S. (1987): Cobalamin-binding protein in gastric juice as a new 
tumor marker in gastric cancer. Cancer Detec. Prev., 10, 285-291.

6. Sekiguchi, M., Sakakibara, K., and Fujii, G. (1978): Establishment of cultured cell lines derived from a human gastric carcinoma. Jpn. J. Exp. Med., 48, 61-68.

7. Chang, T.H., Steplewski, Z., and Koprowski, H. (1980): Production of monoclonal antibodies in serum-free medium. J. Immunol. Methods, 39, 369-375.

8. Steplewski, Z., Chang, T.H., and Koprowski, H. (1981): Release of monoclonal antibodydefined antigens by human colorectal carcinoma and melanoma cells. Cancer Res., 41, 2723-2727.

9. Graesbeck, R., and Kouvonen, I. (1983): The material and processes of intestinal transport, in Methods in Hematology, The Cobalamins, ed. by Hall, C.H., Churchill Livingstone, New York, Vol. 10, pp. 79-108.

10. Jacob, E., and Herbert, V. (1975): Measurement of unsaturated "granulocyte-related" (TC I and TC III) and "liver-related" (TC II) $\mathrm{B}_{12}$ binders by instant batch separation using a microfine precipitate of silica (QUSO G32). J. Lab. Clin. Med., 86, 505-512.

11. Retief, F.P., Gottlieb, C.W., Kocha, S., Pratt, P.W., and Herbert, V. (1967): Separation of vitamin $B_{12}$-binding proteins of serum, gastric juice and saliva by rapid DEAE cellulose chromatography. Blood, 29, 501-516.

12. Allen, R.H., and Majerus, P.W. (1972): Isolation of vitamin $B_{12}$-binding proteins using affinity chromatography. 1. Preparation and properties of vitamin $\mathrm{B}_{12}$ Sepharose. J. Biol. Chem., 247, 7695-7701.

13. Laas, T., and Fast-Johansson, A. (1979): Isoelectric focusing with Pharmalyte ${ }^{\mathrm{TM}}$ in gel rods, in Protides of the Biological Fluids, ed. by Peeters, H., Pergamon Press, Oxford, Vol. 27, pp. 693-697.

14. Morrison, M., and Schonbaum, G.R. (1976): Peroxidase catalyzed halogenation. Annu. Rev. Biochem., 45, 861-888.

15. Kessler, S.W. (1975): Rapid isolation of antigens from cells with a staphylococcal protein A antibody absorbent: Parameters of the interaction of antibody-antigen complexes with protein A. J. Immunol., 155, 1617-1624.

16. Graham, R.C., and Karnovski, M.J. (1966): The early stages of absorption of injected horseradish peroxidase in the proximal tubules of mouse kidney: Ultrastructural cytochemistry by a new technique. J. Histochem. Cytochem., 14, 291.

17. Kudoh, H., Inada, M., Ohshio, G., Wakatsuki, Y., Ogawa, K., Hamashima, Y., and Miyake, T. (1987): Immunohistochemical localization of vitamin $B_{12}$ R-binder in the human digestive tract. Gut, 28, 339-345.

18. Matsukura, N., Suzuki, K., Kawachi, T., Aoyagi, M., Sugimura, T., Kitapka, H., Numajiri, H., Shibata, A., Itabashi, M., and Hirota, T. (1980): Distribution of marker enzymes and mucin in intestinal metaplasia in human stomach and relation of complete and incomplete types of intestinal metaplasia to minute gastric carcinoma. JNCI, 65, 231-240.

19. Burger, R.L., Schneider, R.J., Mehlman, C.S., and Allen, R.H. (1975): Human plasma R-type vitamin $B_{12}$-binding proteins II. The role of transcobalamin I, transcobalamin III, and the normal granulocyte vitamin $\mathrm{B}_{12}$ binding protein in the plasma transport of vitamin $\mathrm{B}_{12} . J$. Biol. Chem., 250, 7707-7713.

20. Yang, S.Y., Coleman, P.S., and Dupont, B. (1982): The biochemical and genetic basis for the microheterogeneity of human R-type vitamin $\mathrm{B}_{12}$ - binding proteins. Blood, 59, 747-755.

21. Hakomori, S. (1985): Aberrant Glycosylation in cancer cell membranes as fucosed on glycolipids: Overview and perspectives. Cancer Res., 45, 2405-2414.

22. Feiz, T. (1985): Demonstration by monoclonal antibodies that carbohydrate structures of glycoproteins and glycolipids are onco-developmental antigens. Nature, 314, 53-57. 